\title{
Inhibition of PIM2 in liver cancer decreases tumor cell proliferation in vitro and in vivo primarily through the modulation of cell cycle progression
}

\author{
PIA KRONSCHNABL ${ }^{1,3}$, ARNOLD GRÜNWELLER $^{2}$, ROLAND K. HARTMANN ${ }^{2}$, \\ ACHIM AIGNER $^{1}$ and ULRIKE WEIRAUCH ${ }^{1}$ \\ ${ }^{1}$ Rudolf-Boehm-Institute for Pharmacology and Toxicology, Clinical Pharmacology, Faculty of Medicine, \\ University of Leipzig, D-04107 Leipzig; ${ }^{2}$ Institute of Pharmaceutical Chemistry, \\ Philipps-University Marburg, D-35037 Marburg, Germany
}

Received February 7, 2019; Accepted June 21, 2019

DOI: $10.3892 /$ ijo.2019.4936

\begin{abstract}
Liver cancer is the fourth leading cause of cancer-related mortality worldwide with limited therapeutic options. Thus, novel treatment strategies are urgently required. While the oncogenic kinase, proviral integration site for Moloney murine leukemia virus 2 (PIM2), has been shown to be overexpressed in liver cancer, little is known about the role of PIM2 in this tumor entity. In this study, we explored the functional relevance and therapeutic potential of PIM2 in liver cancer. Using PIM2-specific siRNAs, we examined the effects of PIM2 knockdown on proliferation (WST-1 assays and spheroid assays), 3D-colony formation and colony spread, apoptosis (flow cytometry and caspase 3/caspase 7 activity), as well as cell cycle progression (flow cytometry, RT-qPCR and western blot analysis) in the two liver cancer cell lines, HepG2 and Huh-7. In subcutaneous liver cancer xenografts, we assessed the effects of PIM2 knockdown on tumor growth via the systemic delivery of polyethylenimine (PEI)-complexed siRNA. The knockdown of PIM2 resulted in potent anti-proliferative effects in cells grown on plastic dishes, as well as in spheroids. This was due to G0/G1 cell cycle blockade and the subsequent downregulation of genes related to the $\mathrm{S}$ phase as well as the $\mathrm{G} 2 / \mathrm{M}$ phase of the
\end{abstract}

Correspondence to: Professor Achim Aigner or Dr Ulrike Weirauch, Rudolf-Boehm-Institute for Pharmacology and Toxicology, Clinical Pharmacology, Faculty of Medicine, University of Leipzig, Haertelstrasse 16-18, D-04107 Leipzig, Germany

E-mail: achim.aigner@medizin.uni-leipzig.de

E-mail: ulrike.weirauch@medizin.uni-leipzig.de

Present address: ${ }^{3}$ Department of Anesthesiology and Intensive Care Medicine, Leipzig University Hospital, Liebigstrasse 20, D-04103 Leipzig, Germany

Key words: PIM2 kinase, liver cancer, hepatocellular carcinoma, liver cancer, siRNA, knockdown, cell cycle, polyethylenimine, polyethylenimine/siRNA nanoplexes cell cycle, whereas the apoptotic rates remained unaltered. Furthermore, colony formation and colony spread were markedly inhibited by PIM2 knockdown. Notably, we found that HepG2 cells were more sensitive to PIM2 knockdown than the Huh-7 cells. In vivo, the therapeutic nanoparticle-mediated delivery of PIM2 siRNA led to profound anti-tumor effects in a liver cancer xenograft mouse model. On the whole, the findings of this study underscore the oncogenic role of PIM2 and emphasize the potential of targeted therapies based on the specific inhibition of PIM2 in liver cancer.

\section{Introduction}

Liver cancer is one of the most frequent malignant tumors with a high prevalence in Eastern and South-Eastern Asia, and rising incidence rates in the Western world. It is the fourth leading cause of cancer-related mortality worldwide, due to high rates of late-stage diagnosis and limited treatment options $(1,2)$. Hence, novel therapeutic strategies targeting oncogenic drivers are warranted.

Proviral integration site for Moloney murine leukemia virus 2 (PIM2) belongs to a family of constitutively active serine/threonine kinases comprising 3 members, PIM1, PIM2 and PIM3. These proto-oncogenes are involved in several cellular processes, including cell survival/apoptosis, cell cycle progression, migration and invasion (3-5). While in some cases they exhibit redundancy and can compensate for one another $(6,7)$, they also have isoenzyme-specific functions $(8,9)$. PIM1 and PIM2 are most frequently deregulated in hematological malignancies, whereas PIM3 is often found to be overexpressed in solid tumors (10). From a therapeutic viewpoint, PIM1 has been explored most extensively so far, with PIM1 inhibitors being tested in clinical studies as a monotherapy or in combined treatment strategies, predominantly in patients with hematological cancers (11).

PIM2 and its role in cancer progression has not yet been studied in detail. It has been shown to synergize with c-MYC to drive lymphomagenesis $(6,12,13)$ in an NF- $\mathrm{NB}$-dependent manner (14) and is overexpressed in multiple myeloma $(7,15,16)$. In ovary and breast tumors, PIM2 has been found to be 
upregulated and to be associated with poor survival rates (17). In tumor entities other than liver cancer, PIM2 has been described to directly interact with and phosphorylate cell cycle regulators, $\mathrm{p} 21^{\mathrm{WAF} 1 / \mathrm{CIP} 1}$ (18) and $\mathrm{p} 27^{\mathrm{KIP} 1}$ (19), as well as the pro-apoptotic protein, BAD (20), thus facilitating cell survival by maintaining mitochondrial potential $(21,22)$. Furthermore, PIM2 has been found to be involved in the negative regulation of the DNA damage response pathway (23) and mediate drug resistance $(24,25)$, as well as invasion $(26,27)$.

In liver cancer, there is evidence to suggest that PIM2 expression is upregulated (28-30), e.g., by inhibiting apoptosis $(29,30)$. As demonstrated in a previous study, upon the stable PIM2 overexpression in normal L02 liver cells, this otherwise non-tumorigenic cell line underwent malignant transformation to form tumor xenografts in a mouse model (31). These observations encouraged us to further explore PIM2 as a potential target for the treatment of liver cancer. However, no specific PIM2 inhibitors are available for functional, mechanistic and therapeutic studies. Thus, we used RNAi-mediated specific PIM2 knockdown for further assessing its functional relevance in liver cancer, and by employing a nanoparticle-based strategy for siRNA delivery in vivo, we also explored its therapeutic potential in a preclinical mouse model.

\section{Materials and methods}

siRNAs and plasmids. A panel of three pre-designed siRNAs was purchased from Thermo Fisher Scientific. The cells were transfected with siRNA targeting PIM2 [siPIM2A: ACC UUCUUCCCGACCCUCAdTdT (sense) and UGAGGG UCGGGAAGA AGGUdTdT (antisense), siPIM2B: CUU GGUUUUACAGGUCAUUdTdT (sense) and AAUGAC CUGUAAAACCAAGdCdT (antisense), siPIM2C: GCC GGGAUUGUCCAAUUACdTdT (sense) and GUAAUU GGACAAUCCCGGCdTdC (antisense) or negative control siRNA (targeting Firefly luciferase mRNA, siCtrl: CUU ACGCUGAGUACUUCGAdTdT (sense) and UCGAAG UACUCAGCGUAAGdTdT (antisense)]. In addition, expression plasmids coding for $\mathrm{p} 21^{\mathrm{WAF} 1 / \mathrm{CIP} 1}, \mathrm{pcDNA} 3.1+\mathrm{p} 21 \mathrm{wt}$ and pcDNA3.1+p21mut were a kind gift from Dr Kurt Engeland and Dr Gerd Müller (Department of Gynecology, University Clinic of Leipzig).

Cell culture and transfection. The liver cancer cell lines, HepG2 and Huh-7, were purchased from the American Type Culture Collection (ATCC). The cell lines were authenticated by STR profiling. The cells were maintained in a humidified incubator under standard conditions $\left(37^{\circ} \mathrm{C}, 5 \% \mathrm{CO}_{2}\right)$ in IMDM (PAA Laboratories supplemented with $10 \%$ fetal calf serum (FCS).

For siRNA transfection, $5 \times 10^{2}$ (HepG2) or $3 \times 10^{2}$ (Huh-7) cells/well were seeded in a 96-well plate, or $3 \times 10^{5}$ (HepG2) or $2 \times 10^{5}$ (Huh-7) cells in a 24-well plate, respectively, and incubated under standard conditions unless stated otherwise. Using the INTERFERin ${ }^{\mathrm{TM}}$ siRNA transfection reagent (Polyplus), $2.5 \mathrm{nM}$ siRNA (for sequences, see Table SI) for proliferation assays or $5 \mathrm{nM}$ siRNA for all other assays were transfected according to the manufacturer's instructions and incubated for the time periods as indicated in the figures. The cells were then analyzed in the well plates or harvested by trypsinization and subsequent transfer to Eppendorf cups and used as described below.

Transfection of $400 \mathrm{ng}$ plasmid DNA per 24 well was performed using FuGENE ${ }^{\circledR}$ transfection reagent (Promega) according to the manufacturer's protocol and incubated at $37^{\circ} \mathrm{C}$ for $6 \mathrm{~h}$, prior to media change and siRNA transfection.

RNA preparation and $m R N A$ detection by $q P C R$. Total cellular RNA was prepared by phenol/chloroform extraction using $250 \mu \mathrm{l}$ TRI-Reagent (Sigma-Aldrich) according to the manufacturer's protocol. cDNA was transcribed from 800 ng RNA using the RevertAid ${ }^{\text {тм }}$ H Minus First Strand cDNA Synthesis Kit (Fermentas). Quantitative PCR was performed in an Applied Biosystems StepOnePlus Real-Time PCR System (Thermo Fisher Scientific) using the PerfeCTa SYBR $^{\circledR}$-Green FastMix ROX (Quantabio). All procedures were conducted according to the manufacturers' protocols with $4 \mu \mathrm{l}$ cDNA (diluted 1:10 with nuclease-free water), $1 \mu \mathrm{l}$ primers ( $5 \mu \mathrm{M}$; see Table SI) and $5 \mu \mathrm{l} \mathrm{SYBR-Green} \mathrm{master}$ mix. A pre-incubation for $15 \mathrm{sec}$ at $95^{\circ} \mathrm{C}$ was followed by 40 amplification cycles: $10 \mathrm{sec}$ at $95^{\circ} \mathrm{C}, 10 \mathrm{sec}$ at $55^{\circ} \mathrm{C}$ and $10 \mathrm{sec}$ at $72^{\circ} \mathrm{C}$. The melting curve for PCR product analysis was determined by rapid cooling down from $95^{\circ} \mathrm{C}$ to $65^{\circ} \mathrm{C}$, and incubation at $65^{\circ} \mathrm{C}$ for $15 \mathrm{sec}$ prior to heating to $95^{\circ} \mathrm{C}$. To normalize for equal mRNA/cDNA amounts, $\mathrm{PCR}$ reactions with target-specific and with actin-specific primer sets were always run in parallel for each sample, and target levels were determined by the $\Delta \Delta \mathrm{Cq}$ method (32).

Western blot analysis. For protein analysis of cell cultures, the cells were seeded and transfected in 24-well plates as described above. At $72 \mathrm{~h}$ after transfection, the medium was removed and the cells were washed once with PBS. $80 \mu 1$ RIPA lysis buffer [50 mM Tris (pH 7.4), $150 \mathrm{mM} \mathrm{NaCl}, 1 \%$ Triton $\mathrm{X}-100,0.5 \%$ sodium deoxycholate, $0.1 \%$ SDS, $2.5 \mathrm{mM}$ sodium pyrophosphate, $1 \mathrm{mM}$ EDTA, $10 \mathrm{mM} \mathrm{NaF}$, Protease Inhibitor Cocktail Set III (EDTA-free, Merck, Darmstadt, Germany), PhosSTOP Phosphatase Inhibitor Cocktail (Roche)] was added per well and plates were incubated on ice for $10 \mathrm{~min}$. The lysate was centrifuged in Eppendorf tubes $\left(9,600 \times \mathrm{g}, 4^{\circ} \mathrm{C}\right.$, $10 \mathrm{~min}$ ) and the supernatant was transferred to a new cup.

To analyze the protein of the tumor samples, small sections of tumor $(\sim 100 \mathrm{mg})$ were homogenized in $15 \mathrm{ml}$ round bottom tubes with $1 \mathrm{ml}$ RIPA lysis buffer, using an Ultra-Turrax (IKA, Staufen, Germany). Lysates were incubated $10 \mathrm{~min}$ on ice prior to transfer to Eppendorf tubes. After centrifugation $\left(9,600 \mathrm{x} \mathrm{g}, 4^{\circ} \mathrm{C}, 10 \mathrm{~min}\right)$, supernatants were transferred to fresh cups, centrifuged once more and supernatants were, again, transferred to fresh cups. The protein concentration was determined using the Bio-Rad DC ${ }^{\mathrm{TM}}$ Protein-Assay (Bio-Rad) according to manufacturer's protocol. Subsequently, 4X loading buffer $(0.25 \mathrm{mM}$ Tris- $\mathrm{HCl}, \mathrm{pH} 6.8,20 \%$ glycerol, $10 \% \beta$-mercaptoethanol, $8 \%$ SDS, $0.08 \%$ bromophenol blue) was added to the samples to yield a $1 \mathrm{X}$ concentration. A volume equivalent to $20 \mu \mathrm{g}$ protein was loaded onto a $10 \%$ polyacrylamide gel, separated by SDS-PAGE, and transferred onto $0.45 \mu \mathrm{m}$ Immobilon $^{\mathrm{TM}}-\mathrm{P}$ Transfer PVDF Membranes (Millipore). The membranes were blocked with a protein-free blocking buffer (Pierce), washed in TBST (10 mM Tris-HCl, 
pH 7.6, $150 \mathrm{mM} \mathrm{NaCl}, 0.1 \%$ Tween-20), and incubated with primary antibodies diluted in blocking buffer: Anti-PIM2 (monoclonal, rabbit anti-human, 1:1,000,\#4730, Cell Signaling Technology), anti-survivin (monoclonal, rabbit anti-human, 1:5,000, GTX62039, GeneTex), anti-PLK1 (monoclonal, rabbit anti-human, 1:1,000, \#4513, Cell Signaling Technology), anti-vinculin (monoclonal, mouse anti-human, 1:5,000, V9131, Sigma-Aldrich) and anti-tubulin (monoclonal, mouse anti-human, 1:2,000, T5168, Sigma-Aldrich). The blots were incubated overnight at $4^{\circ} \mathrm{C}$, washed in TBST and incubated for $1 \mathrm{~h}$ at room temperature with horseradish peroxidase-coupled goat anti-rabbit IgG (1:2,000; Cell Signaling Technology, \#4414) or horseradish peroxidase-coupled goat anti-mouse IgG (1:5,000; Thermo Fisher Scientific, \#31430) in blocking buffer. After washing again, bound antibodies were visualized by enhanced chemiluminescence [ECL kits SignalFire ${ }^{\mathrm{TM}}$ (Cell Signaling) or SuperSignal ${ }^{\circledR}$ West Femto (Thermo Fisher Scientific)]. Scanned bands were quantitated using ImageJ software (National Institutes of Health).

Proliferation assay. At the time points indicated, numbers of viable cells were determined using a colorimetric assay. Briefly, the medium was aspirated from the wells and $50 \mu \mathrm{l}$ of a 1:10 dilution of cell proliferation Reagent WST-1 (Roche Molecular Biochemicals) in serum-free medium was added to the cells, followed by incubation for $1 \mathrm{~h}$ at $37^{\circ} \mathrm{C}$. The absorbance at $450 \mathrm{~nm}$ was measured using an ELISA reader (Asys Hightech).

Colony formation assay. Cell numbers were determined and 400 cells per well were seeded in 6-well plates in triplicates. At the indicated time points, the medium was aspirated and cells were fixed and stained with a crystal violet staining solution [ $0.4 \%$ crystal violet (Roth), 50\% methanol] for $20 \mathrm{~min}$ at room temperature. The staining solution was removed and plates were washed twice with $\mathrm{dH}_{2} \mathrm{O}$. The plates were then left to dry overnight and the number of colonies (a colony defined as $\geq 50$ cells) was counted by the naked eye.

Colony spread assay. The cells were counted and $20 \mu \mathrm{l}$ drops of cell suspension containing 5,000 cells were set in the middle of a well of a new 6-well plate; 3 wells were loaded for each treatment. The cells were allowed to attach for $2 \mathrm{~h}$ at $37^{\circ} \mathrm{C}$ before aspirating excess media and carefully adding $2 \mathrm{ml}$ of fresh media. Following incubation for the time periods indicated in the figures, the medium was removed and the cells were fixed and stained with a crystal violet staining solution for $20 \mathrm{~min}$ at room temperature. After aspirating the staining solution, the plates were washed twice with $\mathrm{dH}_{2} \mathrm{O}$ and allowed to dry overnight. The density of the main colony in the center, as well as the number of distant colonies were determined using ImageJ software (version 1.48).

Spheroid assay. A total of 5,000 cells per well were seeded in ultra-low attachment U-bottom plates (Nexcelom Bioscience) and the spheroid was allowed to form. At the indicated time points, the spheroid size was documented and the spheroid area was measured using a Celigo Imaging Cytometer (Nexcelom Bioscience) and the corresponding software. To determine the amount of dead cells, spheroids were stained with propidium iodide (PI; $10 \mu \mathrm{g} / \mathrm{ml})$ and Hoechst $33342(3 \mu \mathrm{g} / \mathrm{ml})$ for $30 \mathrm{~min}$ at $37^{\circ} \mathrm{C}$. The fluorescence intensity was quantitated with the Celigo Imaging Cytometer (Nexcelom).

Apoptosis analysis. To determine the rate of apoptosis by flow cytometry, the cell suspension was spun down by centrifugation (200 x g, room temperature, $5 \mathrm{~min}$ ). The supernatant was aspirated, the cells were washed with ice-cold PBS and cell numbers were determined. A total of $1 \times 10^{5}$ cells were transferred to fresh Eppendorf tubes and centrifuged (200 x g, room temperature, $5 \mathrm{~min})$. After resuspending the cells in $100 \mu \mathrm{l}$ Annexin V-binding buffer (10 mM HEPES, pH 7.4, $140 \mathrm{mM}$ $\mathrm{NaCl}, 2.5 \mathrm{mM} \mathrm{CaCl}_{2}$ ), $5 \mu \mathrm{l}$ Annexin V-FITC (Thermo Fisher Scientific) was added and the cells were incubated at room temperature for $15 \mathrm{~min}$ in the dark. Subsequently, $2 \mu \mathrm{l}$ of a $2 \mathrm{mg} / \mathrm{ml}$ PI solution was added, as well as another $400 \mu \mathrm{l}$ of Annexin V-binding buffer. The cells were analyzed using an Attune $^{\mathrm{TM}}$ Flow Cytometer (Thermo Fisher Scientific) in the BL1 and BL3 channel.

To determine the activity of effector caspase 3 and caspase 7, the Caspase-Glo ${ }^{\circledR}$ 3/7 Assay (Promega) was used. A total of $2 \times 10^{3}$ cells were seeded in a 96-well plate, transfected as described above, and incubated at $37^{\circ} \mathrm{C}$ for $72 \mathrm{~h}$. The medium was aspirated and caspase substrate was diluted 1:5 in serum-free medium, prior to the addition of $50 \mu \mathrm{l}$ to the cells. Following incubation for $1 \mathrm{~h}$ at room temperature in the dark, luminescence was measured using a Fluostar Optima reader (BMG Labtec). A WST-1 assay was performed in parallel on the same plate to normalize for differences in cell density.

Cell cycle analysis. At $48 \mathrm{~h}$ following transfection, the cells were treated with nocodazole $(100 \mathrm{ng} / \mathrm{ml}$; Roth) to induce a G2/M block. After $20 \mathrm{~h}$, raw cells were trypsinized, transferred to Eppendorf tubes and centrifuged (200 x g, room temperature, $5 \mathrm{~min}$ ). The supernatant was discarded and the cell pellet resuspended in ice cold $70 \%$ ethanol. The cells were fixed for at least $1 \mathrm{~h}$ at $-20^{\circ} \mathrm{C}$ prior to centrifugation as above and were then subjected to RNase digestion $(50 \mu \mathrm{g} / \mathrm{ml}$ RNase A in PBS) for $30 \mathrm{~min}$ at $37^{\circ} \mathrm{C}$. PI solution was added to yield a final concentration of $50 \mu \mathrm{g} / \mathrm{ml}$. Cell cycle distribution was analyzed in the BL2 channel using an Attune ${ }^{\mathrm{TM}}$ Flow Cytometer (Thermo Fisher Scientific).

Mouse xenograft models. Twelve female athymic nude mice (Crl:NU-Foxn1nu, Charles River Laboratories; age, 10 weeks; average weight, $\sim 20 \mathrm{~g}$ ) were housed at $23^{\circ} \mathrm{C}$ in a humidified atmosphere and a 12-h-light/dark cycle, with standard rodent chow and water ad libitum. For tumor establishment, 5x10 HepG2 cells in $150 \mu 1$ PBS were injected subcutaneously (s.c.) into both flanks of the mice. When solid tumor xenografts reached a volume of $\sim 50 \mathrm{~mm}^{3}$, the mice were randomly divided into specific treatment and negative control treatment groups ( 6 mice each, with $n=8$ tumors per group). For polymeric nanoparticle formation, siRNAs were complexed with PEI F25-LMW essentially as previously described (33). Briefly, one treatment, $10 \mu \mathrm{g}$ siRNA was dissolved in $75 \mu \mathrm{l}$ complexation buffer (10 mM HEPES, $150 \mathrm{mM} \mathrm{NaCl}$, pH 7.4) and incubated for $10 \mathrm{~min} .50 \mu \mathrm{g}$ PEI F25-LMW was dissolved in the same buffer, incubated at room temperature for $10 \mathrm{~min}$ and then mixed with the siRNA solution. Aliquots sufficient 
for treating all mice of each group at a given time point were prepared and stored frozen at $-80^{\circ} \mathrm{C}$. Prior to use, the complexes were thawed and incubated at room temperature for 15-30 min. Every 2-3 days, $150 \mu \mathrm{l}$ complex equivalent to $10 \mu \mathrm{g}$ PEI-complexed siRNA was administered by intraperitoneal (i.p.) injection. Tumor volumes were monitored every 2-3 days. The mice were sacrificed one day after the final treatment, and tumors were removed. Sections of the tumor tissue where snap-frozen in liquid nitrogen for RNA or protein preparation.

Statistical analysis. Statistical analyses were performed using the Student's t-test or one-way ANOVA with Tukey's multiple comparison post-test. Values are presented as the means \pm SEM, with ' $n$ ' in the figure legends indicating the number of independent experiments. All independent experiments were performed at least in triplicates. A value of $\mathrm{P}<0.05$ was considered to indicate a statistically significant difference.

\section{Results}

RNAi-mediated knockdown of PIM2 in HepG2 and Huh-7 liver cancer cell lines. As a specific PIM2 inhibitor is not yet available, we selected an RNAi-based knockdown strategy to target PIM2. Three PIM2-specific siRNAs were tested in the liver cancer cell lines, HepG2 and Huh-7. RT-qPCR revealed that all three siRNAs substantially reduced the mRNA levels of PIM2 to comparable extents in both cell lines (Fig. S1A). Transfection with the most efficient siRNA, siPIM2A, reduced the PIM2 mRNA levels by almost $90 \%$, as compared to the negative control siRNA (siCtrl) targeting an unrelated gene (Firefly luciferase). In the case of siPIM2C, residual PIM2 mRNA levels were observed at 30\% (HepG2 cells) and $13 \%$ (Huh-7 cells), while the least efficient siPIM2B still resulted in a $>60 \%$ knockdown in both cell lines. Similar results were obtained at the protein level, as determined by western blot analysis, confirming the substantial downregulation of PIM2 with all PIM2-specific siRNAs and identifying siPIM2A as the most efficient (Fig. 1B). For further experiments, two of the three siRNAs were selected: siPIM2A, as it achieved the most efficient knockdown and siPIM2B, which exhibited a lower knockdown efficiency and was thus able to resolve the association of the PIM2 expression levels with phenotypic effects.

PIM2 knockdown leads to decreased proliferation and impaired colony formation. For the initial assessment of the relevance of PIM2 as a possible target gene in liver cancer therapy, we analyzed the effect of an RNAi-mediated knockdown on cell proliferation in vitro. WST-1 assays in HepG2 cells revealed a profound decrease in cell proliferation in the case of both PIM2-specific siRNAs. In fact, while no non-specific siRNA transfection effects on the PIM2 level were observed (compare siCtrl vs. untreated), PIM2 knockdown essentially led to an arrest in cell proliferation (Fig. 1A, upper graph). By contrast, a similar abolishment of Huh-7 cell proliferation was only observed in the case of the more potent siRNA, siPIM2A, whereas the less potent siRNA, siPIM2B, was not able to inhibit cell proliferation more than the siCtrl (Fig. 1A, lower graph).

The anti-proliferative effects were subsequently tested in a more complex $3 \mathrm{D}$ cell culture system. Compared with
2D cultures, spheroid cultures more closely resemble the in vivo situation with regard to cell-cell and cell-matrix contacts, gradient access to oxygen and nutrient supply. In this experiment, the HepG2 or Huh-7 cells were transfected prior to the generation of spheroids, which were then allowed to grow for 7 days. Compared to the negative controls, the siRNA-mediated knockdown of PIM2 did not alter the shape or formation kinetics (e.g., more rapid or delayed formation; data not shown), but led to significantly smaller HepG2 spheroids. The comparison between the two specific siRNAs also revealed a gene-dose effect, with size reductions of $32 \%$ (siPIM2A) and 21\% (siPIM2B) as compared to the control spheroids (Fig. 1B, upper panel). Similar to the 2D proliferation assay, spheroid sizes of the Huh-7 cells only decreased upon transfection with the more efficient siRNA, siPIM2A (17\% reduction compared to the siCtrl; Fig. 1B, lower panel).

Colony numbers and sizes were also profoundly reduced in the HepG2 cells, with a $>80 \%$ inhibition for both PIM2-specific siRNAs over the siCtrl. As expected, siPIM2A was slightly more efficient than siPIM2B (Fig. 1C, left panels). Again, the siRNA knockdown efficiency was more variable in the Huh-7 cells where, in addition to some rather profound non-specific effects, an almost complete abolishment of colony formation was observed for siPIM2A. The less efficient siPIM2B reduced the colony number by only $\sim 30 \%$ as compared to siCtrl (Fig. 1C, right panels). To investigate this further, we performed colony spread assays. In this experiment, a colony is transferred to the middle of an empty well, is allowed to grow for a specified time period and the establishment of distant colonies is then assessed. Similar to the above-mentioned experiments, it was observed that the primary colony sizes were smaller in the siRNA-treated HepG2 (both siRNAs) and Huh-7 cultures (siPIM2A only; Fig. 1D, cell staining images). Additionally, decreases in the number of distant colonies were also observed (Fig. 1D, bar diagrams). It should also be noted that the densities of the primary colonies were decreased in the siPIM2-treated cells compared to the control treatment. This was observed for the HepG2 cells treated with both PIM2 siRNAs and in the Huh-7 cells exposed to the more potent siRNA, siPIM2A, while the less potent siRNA, siPIM2B, again exerted no marked effect (Fig. S2).

The combined observations of this experiment suggest that Huh-7 cells are less sensitive to PIM2 knockdown, with higher reductions in PIM2 expression were required in this cell line to obtain inhibitory effects. Due to the observed non-specific transfection effects, it was not possible to further increase the siRNA amounts. This emphasizes the need for high efficiency siRNAs in Huh-7 cells, while this was found to be less critical for the HepG2 cells.

Rate of apoptosis is not affected by knockdown of PIM2. Subsequently, we examined whether the inhibitory effects of PIM2 knockdown may at least in part be due to elevated cell death, since the evasion of apoptosis is one of the hallmarks of cancer cells, and PIM2 kinase has been described to be involved in this process $(16,21)$. To this end, we first examined changes in the proportion of apoptotic cells in the cell population. Using flow cytometry, no significant elevation in the numbers of Annexin-V-positive and PI-negative cells was detected upon siPIM2 transfection in both cell lines 

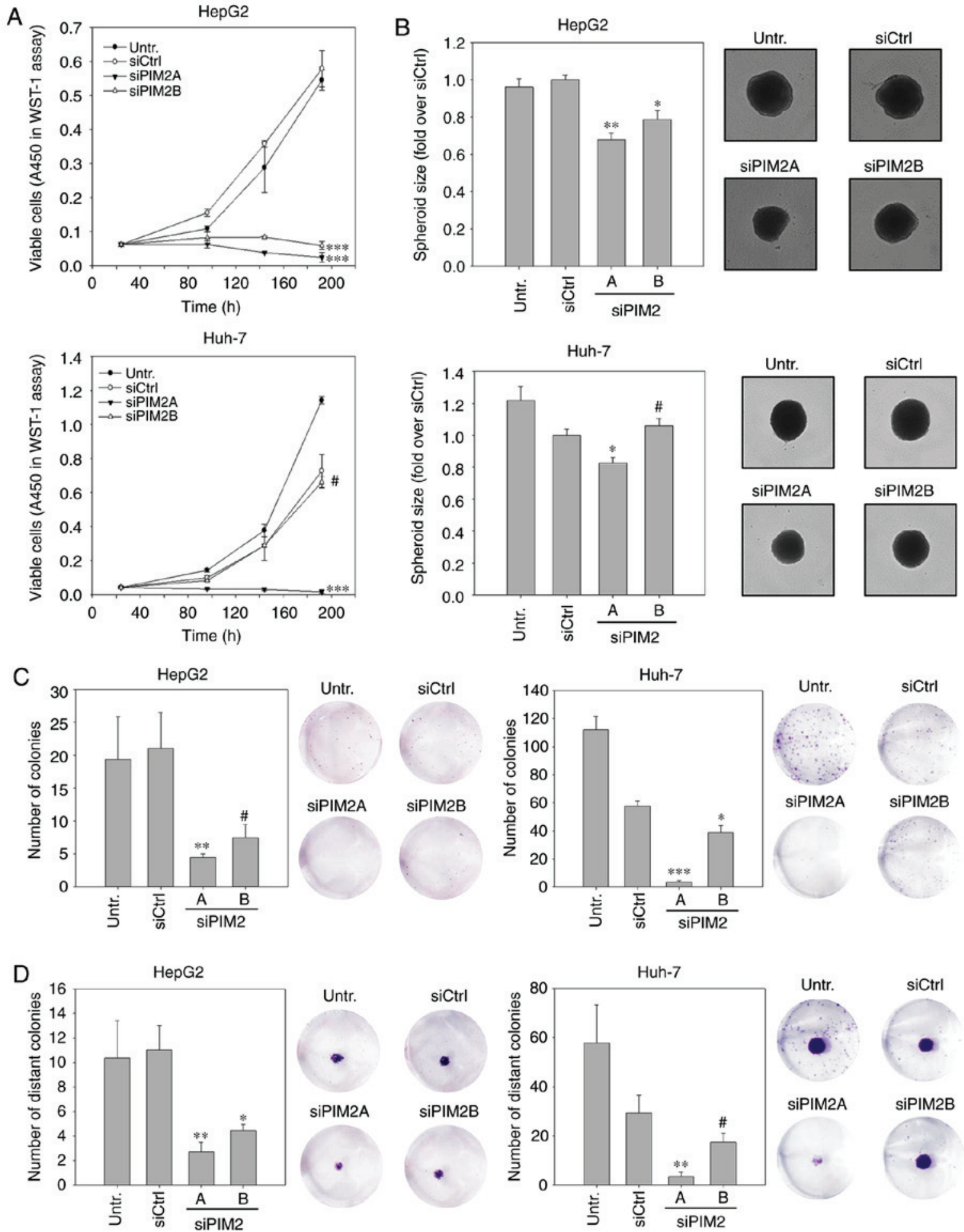

Figure 1. Effect of PIM2 knockdown on proliferation and colony formation in HepG2 and Huh-7 liver cancer cell lines. (A) WST-1 viability assay was performed at the indicated time points. A representative example of 3 independent experiments is shown. (B) Cells were transfected $48 \mathrm{~h}$ prior to seeding them into ultra-low attachment plates for spheroid formation. Spheroid size was documented and quantitated after 7 days $(\mathrm{n}=3)$. Images show representative examples. (C and D) Cells were transfected and $48 \mathrm{~h}$ later, colony formation was determined by performing (C) colony formation assays and (D) colony spread assays. After 7 days, the number of (distant) colonies were counted $(\mathrm{n}=4)$. Images show representative wells. ${ }^{*} \mathrm{P}<0.05,{ }^{* * *} \mathrm{P}<0.01$ and ${ }^{* * * *} \mathrm{P}<0.001$, significant differences compared to the siCtrl; the hash symbol (\#) indicates that there were no significant differences. PIM2, proviral integration site for Moloney murine leukemia virus 2 .

(Figs. 2A and S3). When examining the effects of PIM2 knockdown in HepG2 cells on the effector caspases of intrinsic and extrinsic apoptosis pathways, caspases 3 and 7, we only found a marginal increase in caspase activity upon siPIM2 transfection in comparison to the siCtrl (Fig. 2B, left graph). However, siPIM2A transfection in the Huh-7 cells led to a 
A

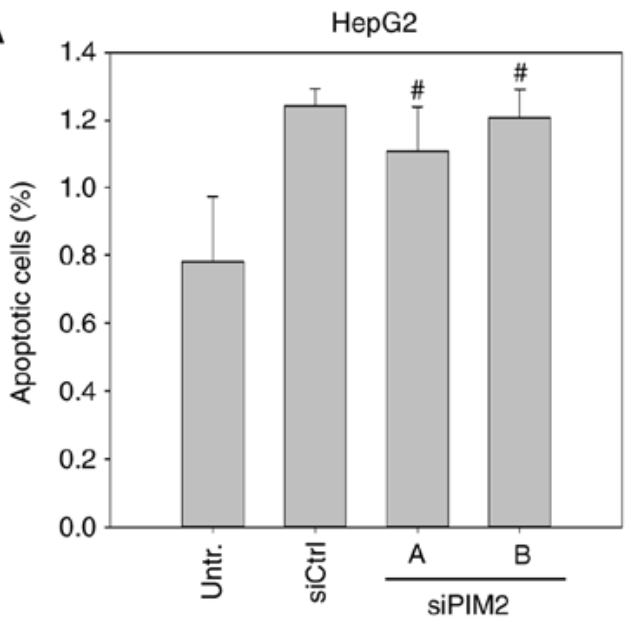

B

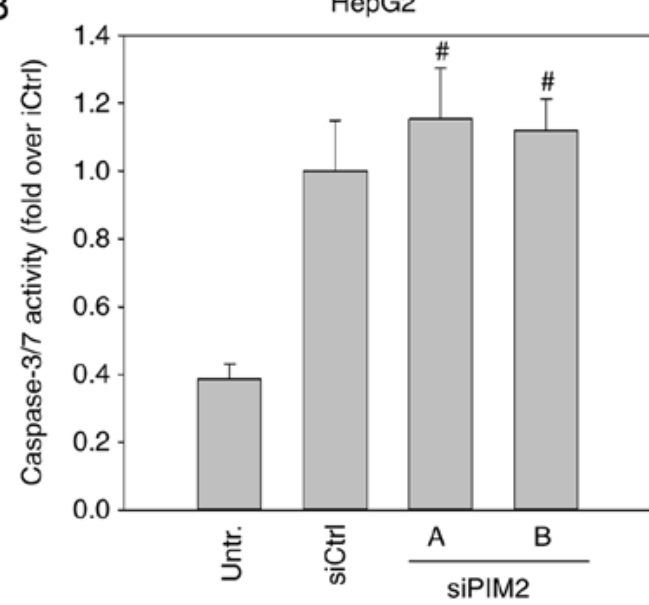

C

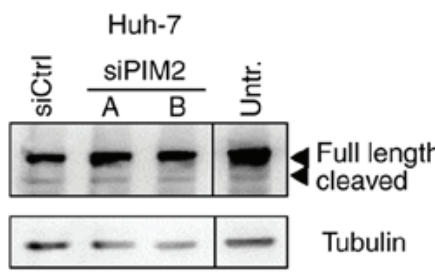

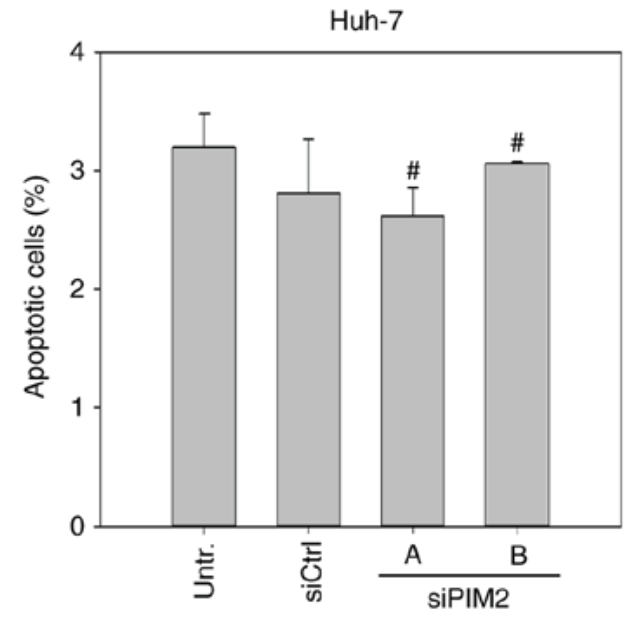
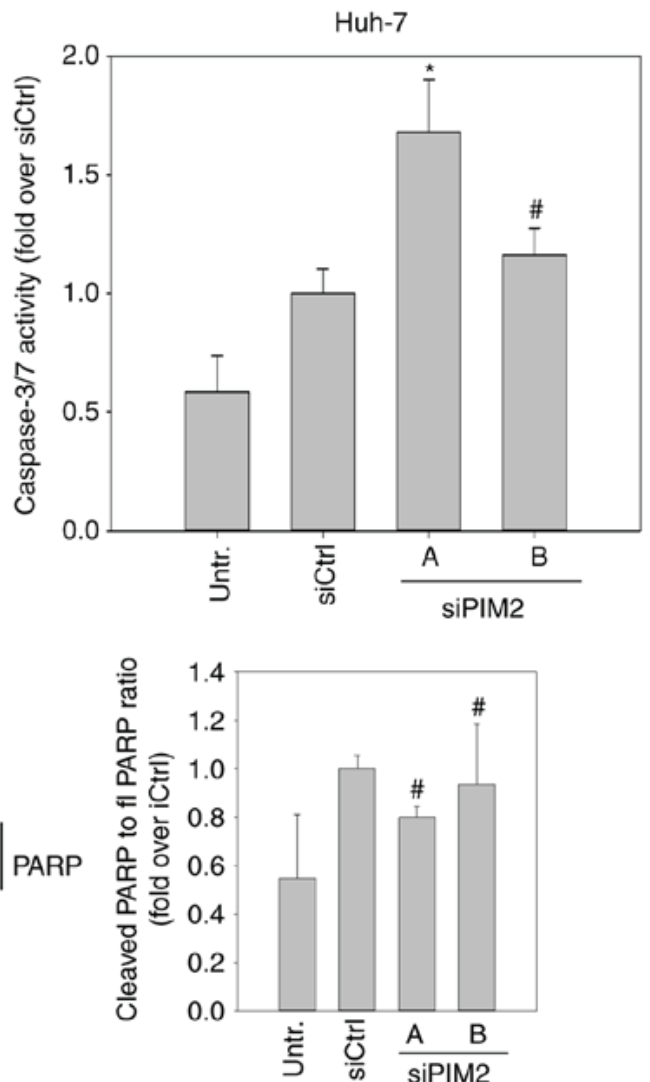

D

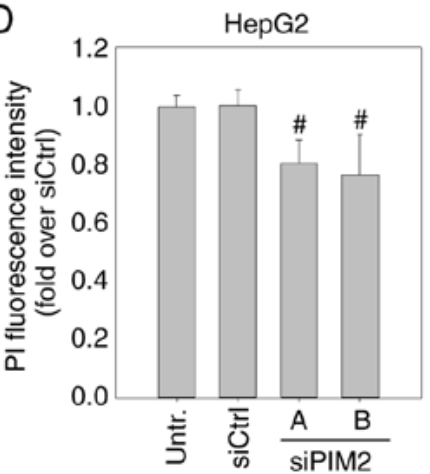

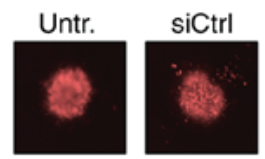

SiPIM2A SiPIM2B

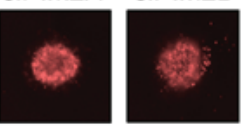

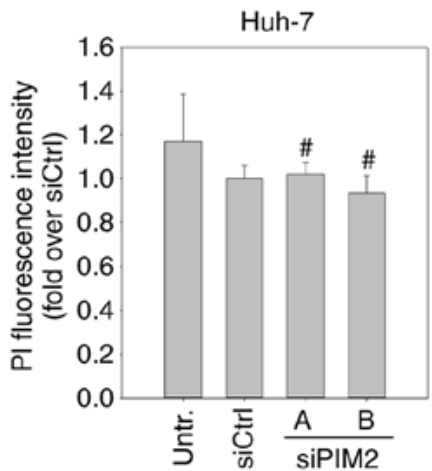

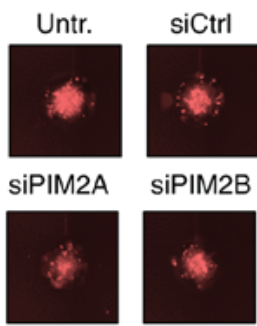

Figure 2. Role of PIM2 knockdown in apoptosis and cell death of HepG2 and Huh-7 liver cancer cell lines. (A) Cells were transfected and stained 48 h later with Annexin V-FITC and PI and underwent FACS analysis. The amount of apoptotic cells (Annexin-V-positive and PI-negative) was determined ( $=3$ ). (B) Measurement of the activity of effector-caspases caspase 3 and caspase 772 h post-transfection ( $\mathrm{n}=3$ ). (C) Protein expression of full length PARP and cleaved PARP in Huh-7 was examined by western blot analysis. A representative blot is shown (black lines indicate where an irrelevant lane was cut out). Bands were quantitated with ImageJ and the ratio of cleaved to full length PARP was calculated (n=2). (D) Cells were transfected and seeded into ultra-low attachment plates after $48 \mathrm{~h}$ for spheroid formation. Spheroids were stained with PI after 7 days $(\mathrm{n}=3)$. Images show representative examples. ${ }^{*} \mathrm{P}<0.05$, significant differences compared to the siCtrl; the hash symbol (\#) indicates that there were no significant differences. PIM2, proviral integration site for Moloney murine leukemia virus 2; PARP, poly (ADP-ribose) polymerase. 
significant $(\sim 30 \%)$ induction of caspase 3/7 activity (Fig. 2B, right graph). To address the discrepancy between the unaltered numbers of apoptotic Huh-7 cells and the elevated caspase 3/7 activity upon siPIM2A transfection, we performed a western blot analysis of poly(ADP-ribose)-polymerase (PARP), a downstream target of caspases 3 and 7. Notably, no increase in PARP cleavage was detected following PIM2 knockdown, indicating that the measured elevation in caspase activity was not sufficient to mediate apoptosis in Huh-7 cells (Fig. 2C). In spheroid cultures stained with PI for the detection of dead cells, again no effect of PIM2 knockdown on cell death was found (Fig. 2D).

Collectively, these data suggest that the induction of apoptosis is not a key mechanism of cell inhibition upon PIM2 knockdown, which in turn indicates that the main functional consequence of PIM2 overexpression in liver cancer is not the increase of cell survival/resistance to cell death.

Cell cycle block in G0/G1 phase upon PIM2 knockdown. In view of the absence of major effects of PIM2 knockdown on apoptosis, the observed reduction in cell proliferation following treatment could be due to the deceleration of the cell cycle. To assess this, $48 \mathrm{~h}$ following siRNA transfection, the cells were treated with nocodazole, which interferes with the polymerization of microtubules and thus blocks the cells in the G2/M phase. By determining cell cycle distribution at a defined time point $(20 \mathrm{~h})$ following the addition of nocodazole, the proportion of cells in the G2/M phase was quantified. Higher percentages indicated a more rapid cell cycle progression, while lower proportions denoted a decelerated cell cycle progression. In the case of untransfected cells or those transfected with a negative control, almost $80 \%$ of the cell population were found to be in the $\mathrm{G} 2 / \mathrm{M}$ phase, with $<20 \%$ remaining in the G0/G1 phase (Fig. 3A, left panels). By contrast, following the knockdown of PIM2, only 50\% of the cells had progressed to the G2/M phase, while a similar percentage was still in the G0/G1 phase. This was true for both PIM2-specific siRNAs in HepG2 cells, while in the Huh-7 cells, a reduced cell cycle progression (i.e., the number of cells in $\mathrm{G} 2 / \mathrm{M}<\mathrm{G} 0 / \mathrm{G} 1$ ) was only observed following transfection with the more potent siRNA, siPIM2A (Fig. 3A, right panels).

To investigate the underlying molecular effects of the reduced cell cycle progression upon PIM2 knockdown and possible differences between the two cell lines, we quantified the mRNA levels of proteins known to play a critical role in cell cycle regulation. More specifically, we performed RT-qPCR for G0/G1 phase-[cyclin E2, cyclin-dependent kinase (CDK) 4 and CDK6] S phase-(cyclin A2 and CDK2) and G2/M phase-related genes (cyclin B1, CDK1 and Survivin). Additionally, the expression the of G2/M phase-related genes, Survivin and Polo-like kinase 1 (PLK1), was examined at the protein level by western blot analysis. In the HepG2 cells, PIM2 knockdown resulted in a decreased expression of all $\mathrm{S}$ phase- and G2/M phase-related genes examined, with the mRNA levels reflecting the respective knockdown efficiencies of siPIM2A and siPIM2B, as also observed above (Fig. 3B). At the protein level, a marked downregulation in the levels of Survivin and PLK1 was observed in the HepG2 cells (Fig. 3B, lower right panel). By contrast, the levels of the G0/G1 phase-related genes in the Huh-7 cells were only marginally affected by PIM2 knockdown or not at all, with some statistically non-significant minor reductions in the mRNA levels of CDK4 and CDK6 upon transfection with the more potent siRNA, siPIM2A. A significant decrease in mRNA expression was only observed for the $\mathrm{S}$ phase-related genes, cyclin A2 and CDK2 (Fig. 3C). Western blot analysis of the G2/M phase-related genes, Survivin and PLK1, revealed only minor reductions in expression levels compared to control treatments, and again only for the more potent siRNA, siPIM2A.

It was hypothesized that the differences between the cell lines, HepG2 and Huh-7, may be dependent on the expression of the cell cycle regulator, p21 ${ }^{\mathrm{WAF} / \mathrm{CIP} 1}$, since HepG2 and Huh-7 cells differ in their status of p53, a known transcriptional regulator of $\mathrm{p} 21^{\mathrm{WAF} 1 / \mathrm{CIP} 1}$ (HepG2, p53 wild type; Huh-7, p53 mutated). Indeed, we found that the $\mathrm{p} 21^{\mathrm{WAF} 1 / \mathrm{CIP1}} \mathrm{mRNA}$ levels were 30 -fold higher in the HepG2 cells as compared to the Huh-7 cells (Fig. S4A). Recently, Liu et al reported that PIM2 induced cell cycle arrest in the G0/G1 phase via p53-independent, but $\mathrm{p} 21^{\mathrm{WAF} / \mathrm{CIP} 1}$-dependent signaling in lung cancer cell lines (34). Thus, in this study, we examined whether the restoration of $\mathrm{p} 21^{\mathrm{WAF} / \mathrm{CIP} 1}$ expression in the Huh-7 cells would enable a more sensitive cell cycle regulation following PIM2 knockdown. Expression plasmids encoding either wild-type (wt) or mutated, non-functional (mut) $\mathrm{p} 21^{\mathrm{WAF} / / \mathrm{CIP} 1}$ were transfected into the Huh-7 cells followed by siRNA transfection, nocodazole treatment and the analysis of cell cycle distribution as described above. The ectopic expression of $\mathrm{wt} \mathrm{p} 21^{\mathrm{WAF} 1 / \mathrm{CIP} 1}$ attenuated cell cycle progression, as compared to the cells transfected with $\mathrm{p} 21^{\mathrm{WAF} / / C I P 1}$ mut (Fig. S4B, black bars indicating more cells in the G0/G1 phase and fewer cells in the G2/M phase). This is in line with findings in the study by Yew et al in multipotent stroma cells, where $\mathrm{p} 21^{\mathrm{WAF} 1 / \mathrm{CIP1}}$ knockdown cells exhibited an accelerated cell cycle progression compared to the control cells (35). Upon PIM2 knockdown in the Huh-7 cells, the $\mathrm{p} 21^{\mathrm{WAF} 1 / \mathrm{CIP} 1}$ wt-transfected cells exhibited a minor further decrease in cell cycle progression, while the effect in the $\mathrm{p} 21^{\mathrm{WAF} / \mathrm{CIP} 1}$ mut transfected counterparts was weaker and observed exclusively in the siPIM2A-transfected cells. This finding indicates that the effects of PIM2 knockdown on the cell cycle are only marginally dependent on $\mathrm{p} 21^{\mathrm{WAF} / \mathrm{CIP} 1}$ in liver cancer.

PIM2 knockdown leads to antitumor effects in vivo. Finally, to assess whether the profound anti-proliferative, tumor cell-inhibitory and cell cycle blocking effects of PIM2 knockdown in HepG2 cells are applicable to the in vivo situation, we explored a therapeutic PIM2 knockdown in a murine tumor xenograft model. Following the establishment of subcutaneous (s.c.) HepG2 tumor xenografts in nude mice, the animals were randomly divided into groups and treated systemically by i.p. injection 3x/week with either polyethylenimine (PEI)-complexed siPIM2A (specific treatment) or PEI-complexed siCtrl (negative control). Over a period of 13 days, tumor xenografts in the mice treated with negative control PEI/siRNA complexes grew by a factor of $\sim 7$, from $\sim 200 \mathrm{~mm}^{3}$ to a mean tumor volume of almost $1,400 \mathrm{~mm}^{3}$. By contrast, the administration of PEI/siPIM2A complexes substantially decreased tumor growth rates, with mean tumor volumes only reaching $600 \mathrm{~mm}^{3}$ in the same time period (Fig. 4A). The effects on tumor growth were already visible 

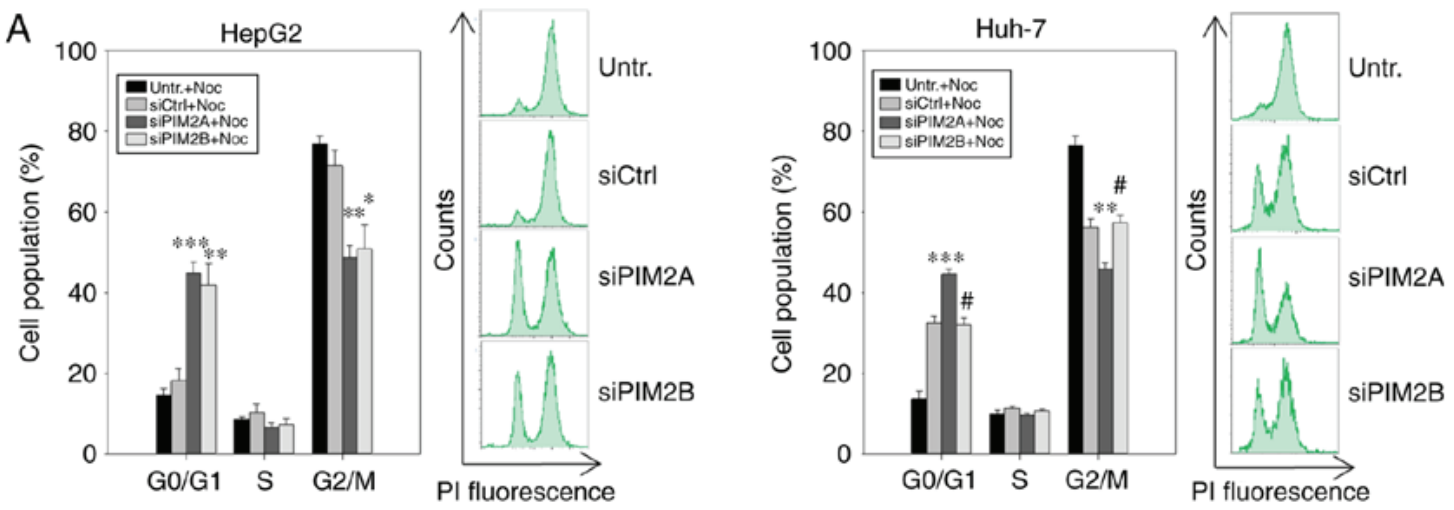

B

G0/G1
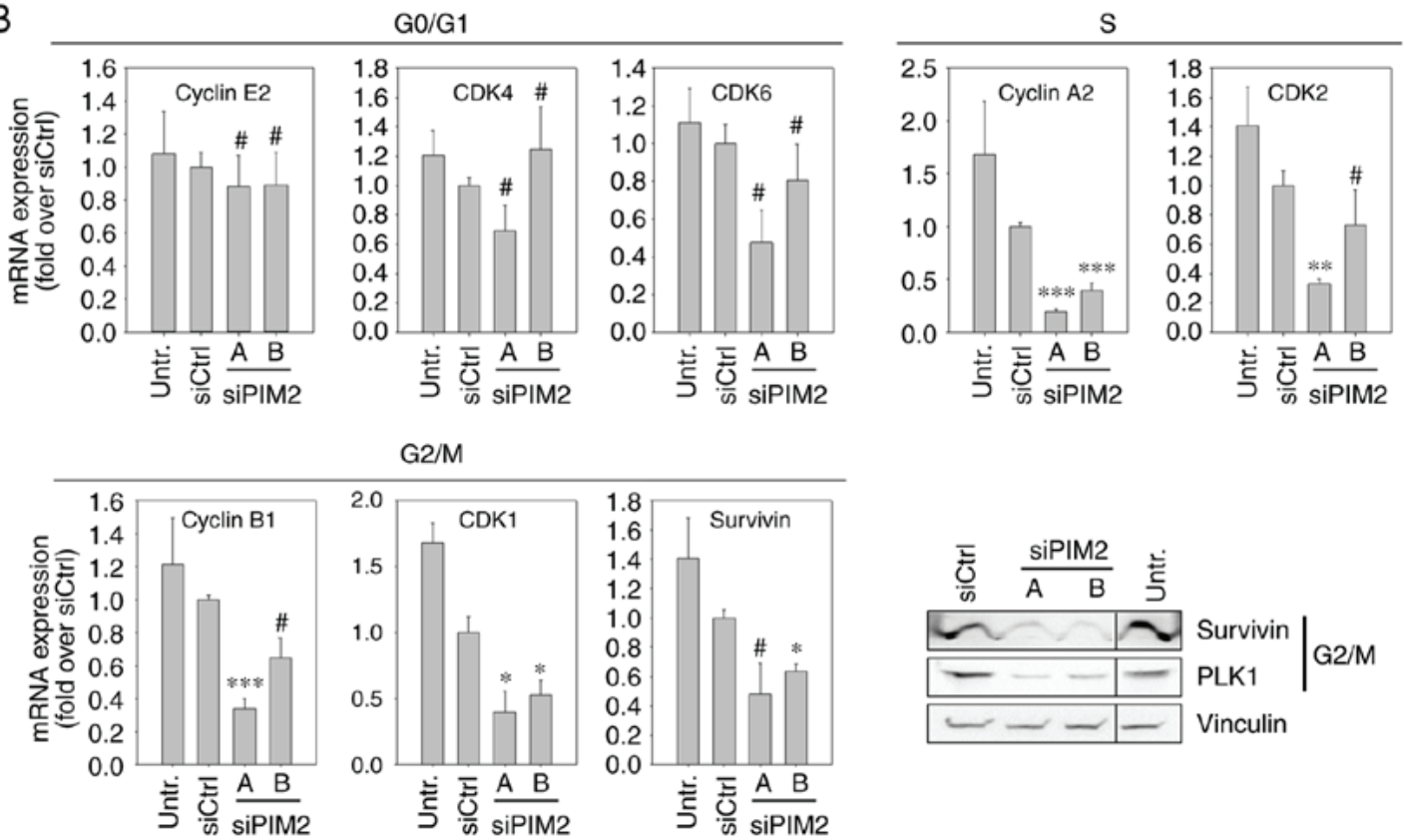

$\mathrm{G} 2 / \mathrm{M}$
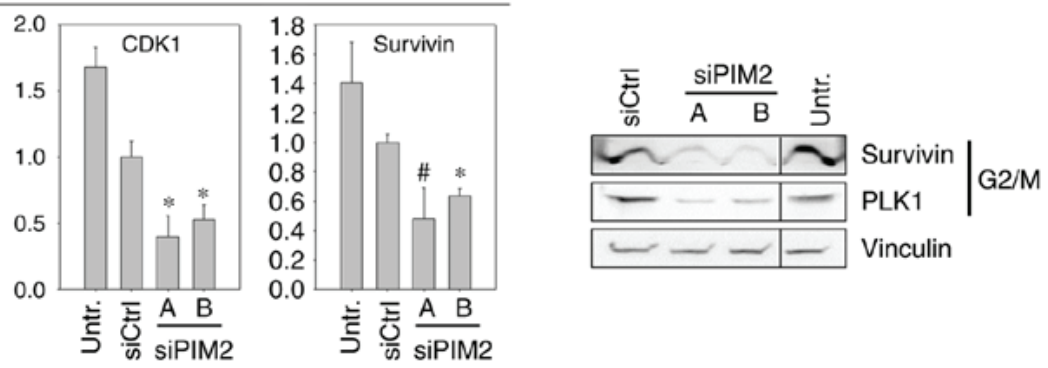

C

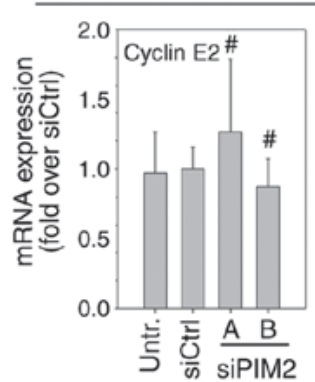

G0/G1
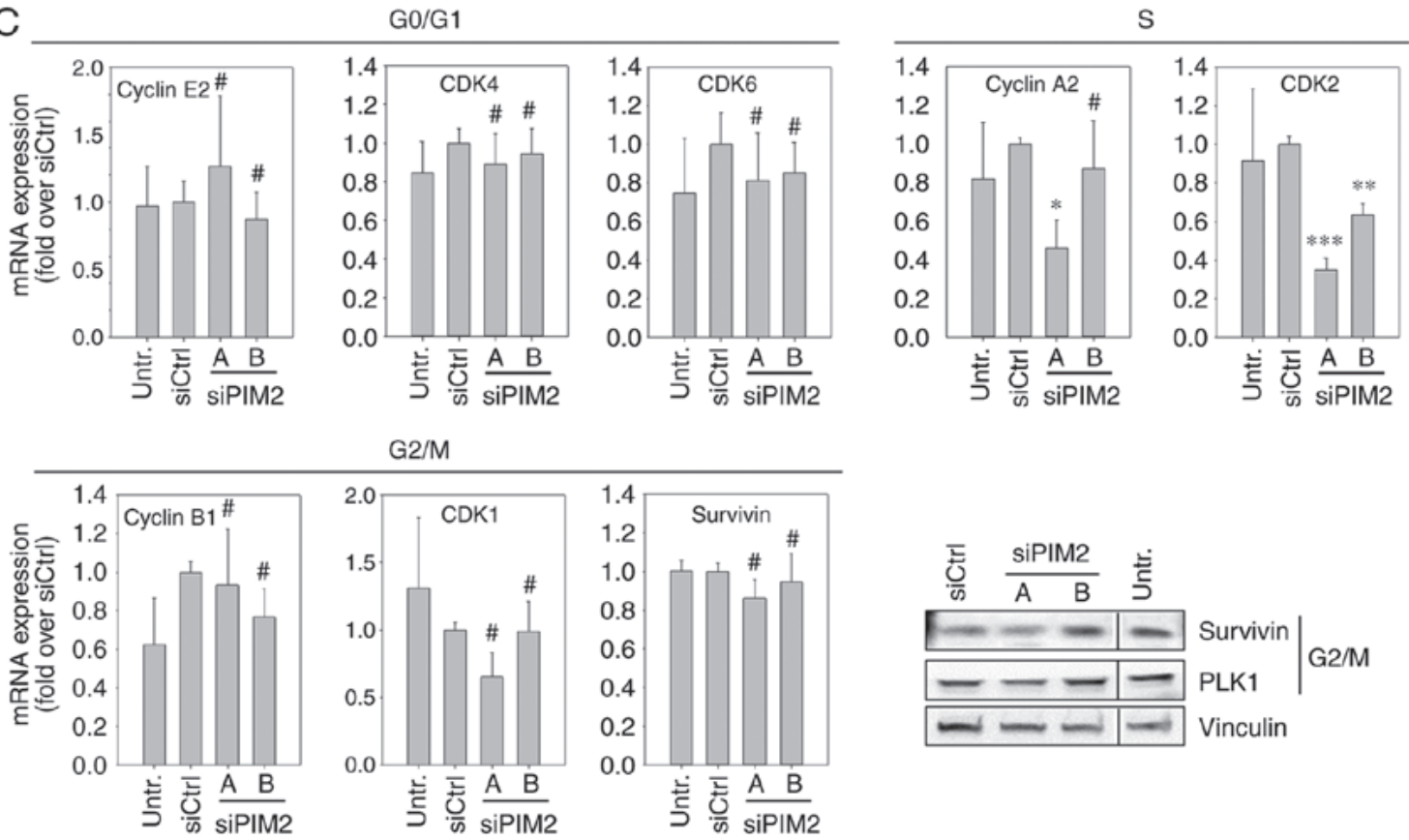

$\mathrm{G} 2 / \mathrm{M}$
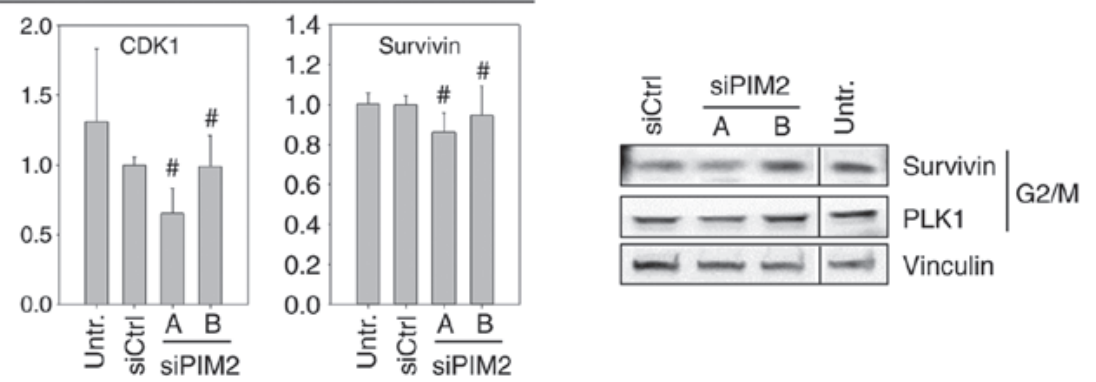

Figure 3. Influence of PIM2 knockdown on the cell cycle of lines HepG2 and Huh-7 liver cancer cells. (A) Cell cycle distribution with nocodazole treatment was analyzed by FACS $72 \mathrm{~h}$ following transfection $(\mathrm{n}=4)$. Representative plots are shown. (B and C) The expression of cell cycle-related genes was analyzed at the RNA level by RT-qPCR (bar graphs, $\mathrm{n}=3$ ) and at the protein level by western blot analysis (representative blots are shown), at $48 \mathrm{~h}$ or $72 \mathrm{~h}$ following transfection, respectively in (B) the HepG2 and (C) the Huh-7 cells. The black lines in the western blots indicate where an irrelevant lane was cut out. "P<0.05, ${ }^{* *} \mathrm{P}<0.01$ and ${ }^{* * *} \mathrm{P}<0.001$, significant differences compared to the siCtrl; the hash symbol (\#) indicates that there were no significant differences. PIM2, proviral integration site for Moloney murine leukemia virus 2. 

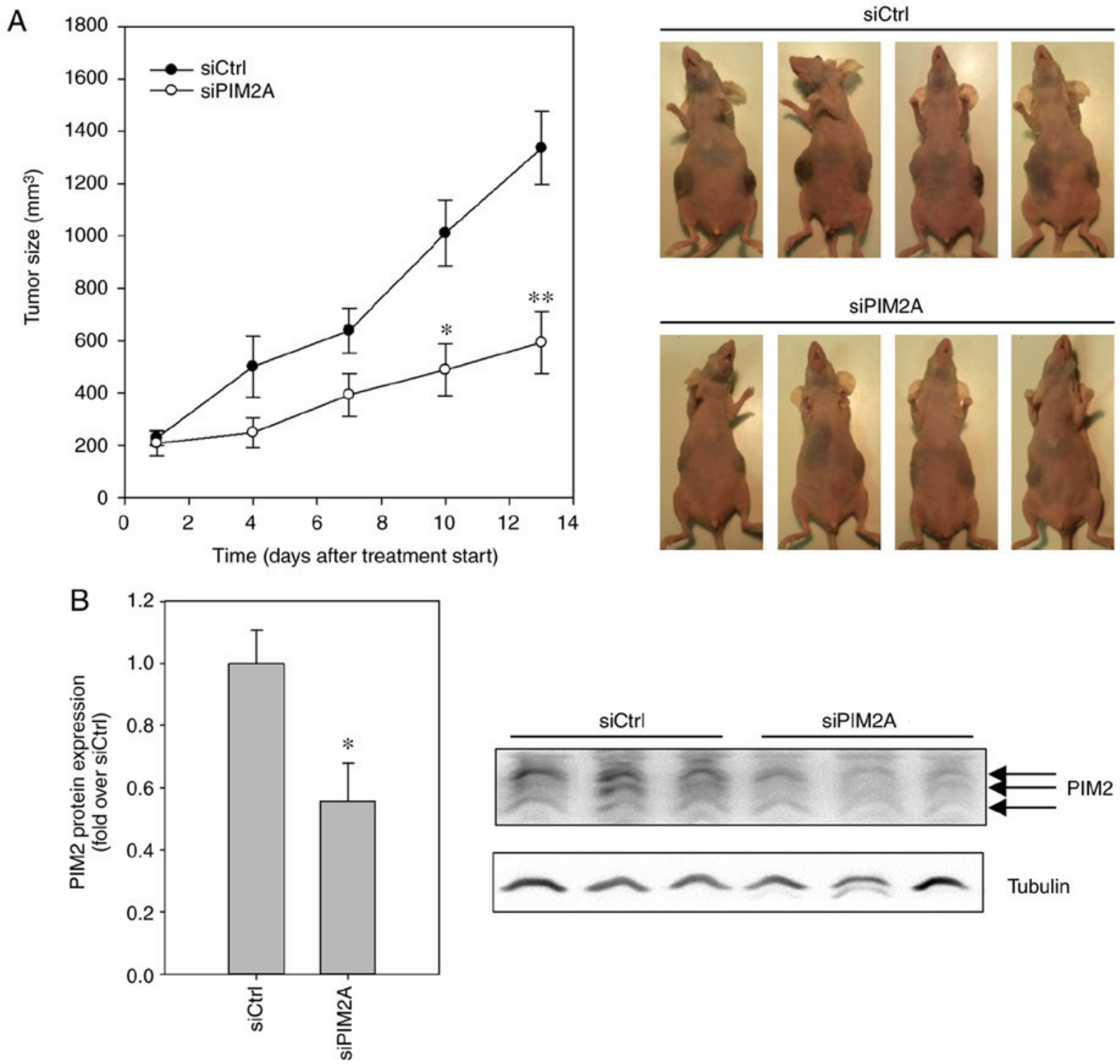

Figure 4. Effect of PIM2 knockdown on tumor growth in a mouse model of subcutaneous xenografts. (A) Subcutaneous HepG2 tumor xenografts were treated with siRNA-loaded nanoplexes via intraperitoneal injection. Growth of tumors was monitored by measurement of tumor size at the indicated time points. Representative examples of mice are shown. (B) Tumors were resected and PIM2 protein expression was determined by western blot analysis. The representative blot shows PIM2 in representative tumor samples. ${ }^{*} \mathrm{P}<0.05,{ }^{* *} \mathrm{P}<0.01$ and ${ }^{* * *} \mathrm{P}<0.001$, significant differences compared to the siCtrl. PIM2, proviral integration site for Moloney murine leukemia virus 2.

at day 4 after commencing treatment and reached statistical significance at day 10 . The treatment, involving repeated injection and systemic delivery of the PEI/siRNA nanoplexes, was well-tolerated, with no obvious side-effects (e.g., alterations in mouse body weight or behavior, or other signs of discomfort). Upon termination of the experiment, the analysis of PIM2 expression levels by western blot analysis revealed a significant $\sim 50 \%$ reduction of PIM2 levels in the tumors of the mice treated with PEI/siPIM2A nanoplexes, as compared to the tumor xenografts from the mice in the negative control group (Fig. 4B). This confirmed that the observed antitumor effect was indeed caused by the efficient knockdown of PIM2.

\section{Discussion}

The overexpression of the survival kinase, PIM2, is found in hematopoietic malignancies and solid tumors, and has been associated with a poor prognosis $(10,36)$. In liver cancer, PIM2 is overexpressed as well, but little is known about the functional relevance of PIM2 in this tumor entity. This study demonstrates that a specific knockdown of PIM2 exerts tumor cell-inhibitory effects in various in vitro settings, as well as in an animal in vivo model.

The evasion of apoptosis has been described in various tumor entities as one of the mechanisms through which members of the PIM protein family promote cell survival $(5,10)$. PIM2 has mostly been described as an anti-apoptotic mediator $(7,16,21,22,29,30)$, but controversially, in some reports, positive $(18,37)$ or no effects on apoptosis have been described as well $(15,38,39)$. This indicates that the role of PIM2 in apoptosis is context-dependent. In HepG2 cells, two studies have described higher apoptosis rates, as well as lower p-4E-BP and p-BAD levels upon siRNA-mediated PIM2 knockdown $(29,30)$. By contrast, in this study, we did not observe 
the induction of apoptosis or cell death upon PIM2 reduction, neither in 2D nor in 3D cell cultures. These contradictory findings may be due to different cell culture conditions in terms of media composition and FCS in particular, since differences in growth factor and cytokine levels may exist between different brands and even batches of FCS. In support of this hypothesis, Gong et al demonstrated that HepG2 cells are less sensitive to apoptosis mediated by PIM2 knockdown in the presence of IL-3 (30), a finding shared by Fox et al, who reported that PIM2 maintained a hyperphosphorylated state of 4E-BP upon IL-3 withdrawal in the murine pro-B cell line FL5.12 (21).

The potent negative effect on cell proliferation by PIM2 knockdown observed in this study may be attributed to a substantial block of the cell cycle in the G0/G1 phase in HepG2 cells. In line with these findings, Kreuz et al reported that PIM2 knockdown in Burkitt's lymphona cells was mainly associated with a cell cycle block in G0/G1 rather than induction of apoptosis (39). Accompanying this cell cycle block, in this study, we observed a decrease in the expression of S phaseand $\mathrm{G} 2 / \mathrm{M}$ phase-related genes. To the best of our knowledge, this is the first time that a broad influence of PIM2 on the expression of cyclins, CDKs, and other cell cycle-related genes is described. One of these genes is the mitosis and cytokinesis regulator, PLK1, that functions as an oncogene in liver cancer and is overexpressed in this tumor entity $(40,41)$. In this study, we found PLK1 to be downregulated upon PIM2 knockdown, whereas Adam et al (38) recently described the colocalization of PLK1 and PIM2 following combined PIM1/PIM2 knockdown in HeLa cells, as well as the dephosphorylation of PLK1 that led neither to decreased PLK1 levels nor affected cell cycle distribution. The results of this study underscore the potential of PIM2 to regulate the cell cycle and to interfere with PLK1 oncogenic pathways via different mechanisms.

The two liver cancer cell lines that were investigated in this study, HepG2 and Huh-7, exhibited varying sensitivities towards the knockdown of PIM2, as determined by decreased proliferation rates and a decelerated cell cycle progression. One explanation we considered relies on the differential expression of the cell cycle inhibitor, $\mathrm{p} 21^{\mathrm{WAF} 1 / \mathrm{CIP} 1}$, which is dependent on the p53 status of the cells and seems to make HepG2 cells with wt $\mathrm{p} 53$ and thus higher $\mathrm{p} 21^{\mathrm{WAF} 1 / \mathrm{CIP} 1}$ expression more sensitive to PIM2 knockdown than Huh-7 with mutant p53 and a low $\mathrm{p} 21^{\mathrm{WAF} 1 / \mathrm{CIP} 1}$ expression. This is in line with the findings of Liu et al, who described a p21 $1^{\mathrm{WAF} 1 / \mathrm{CIP1}}$-dependent cell cycle block in G0/G1 upon PIM2 knockdown in the non-small cell lung cancer cell lines A549 and H1299 (34). However, our findings in the Huh-7 cells also suggest an additional, $\mathrm{p} 21^{\mathrm{WAF} 1 / \mathrm{CIP}}$-independent mechanism of the cell cycle regulation by PIM2 in liver cancer cells, since the ectopic overexpression of wt $\mathrm{p} 21^{\mathrm{WAF} 1 / \mathrm{CIP} 1}$ in this cell line led to an only slight increase in sensitivity towards PIM2 knockdown. Another difference between the HepG2 and Huh-7 cells is in their $\beta$-catenin status. There is increasing evidence that the deregulation of the $\mathrm{Wnt} / \beta$-catenin signaling pathway is involved in liver cancer tumorigenesis $(42,43)$. Approximately $50 \%$ of liver cancers are characterized by the nuclear accumulation of active $\beta$-catenin. HepG 2 carries mutated $\beta$-catenin heterozygously (one wild-type and one mutated allele), with the concomitant deletion of aa25-140 resulting in the activation of the protein and a strong nuclear accumulation (44), but also in a further decrease of its already low expression levels. By contrast, Huh-7 cells carry stabilized wild-type $\beta$-catenin and express higher levels of total and activated $\beta$-catenin (45). Nuclear, active $\beta$-catenin is involved in cell cycle progression and its expression peaks in G2/M (46). Possibly, the lower amount of active $\beta$-catenin may render HepG2 cells by a yet unknown crosstalk more sensitive to cell cycle deceleration upon PIM2 knockdown, suggesting that the PIM2-mediated cell cycle block in liver cancer cells may be $\beta$-catenin-dependent. Thus, future studies are warranted to explore and extensively characterize a possible synergistic effect between PIM2 and $\beta$-catenin in a combined knockdown strategy.

Another explanation as to why Huh-7 cells exhibit less cell inhibition and effects on cell cycle upon PIM2 knockdown compared to the HepG2 cells may related to the expression patterns of the three PIM2 isoforms. They arise from three different translation start sites on the same mRNA. In murine cells, isoforms $1(40 \mathrm{kDa})$ and $2(37 \mathrm{kDa})$ result from the utilization of non-classical CUG translation initiation codons. The first AUG codon gives rise to isoform 3 (34 kDa), but is not embedded in a Kozak sequence and thus translated with low efficiency (12). For isoform 3, pro-apoptotic and cell cycle inhibiting effects upon its ectopic expression were described in cancer cell lines $(18,37)$, antagonizing the otherwise oncogenic activity of total PIM2 protein. In this study, by western blot analyses, we found a higher proportion of expression of the $34 \mathrm{kDa}$ isoform in Huh-7 cells than in HepG2 cells, which may result in the less pronounced antiproliferative effects of PIM2 knockdown in Huh-7 cells observed in our experiments. By contrast, however, Yan et al found the anti-apoptotic effects of the $34 \mathrm{kDa}$ PIM2 isoform in the non-cancerous murine hematopoietic cell line, FDCP1, upon IL-3 withdrawal (20), suggesting the distinction between the roles of the different isoforms to be more complex. Further studies are required, in which single isoform knockdown strategies may help elucidate the individual roles of the three PIM2 isoforms.

The profound effects of PIM2 knockdown on the number of distant colonies in our colony spread assays gives rise to the notion that PIM2 not only influences colony formation, but may enable cells to disseminate to form new colonies, which is crucial for metastasis. Cellular alterations in the potential to detach, disseminate, migrate and/or re-attach at a new site may have contributed to the phenotypic observations. A deeper understanding of the mechanisms of migration and invasion leading to metastasis in liver cancer, and the possible role of PIM2 in these processes, is crucial, since the disease is often diagnosed at late stages when patients have already developed extrahepatic metastases predominantly located in the lung, lymph nodes, and bone, and treatment options are thus limited (47). In contrast to PIM1 and PIM3, very little is known regarding the impact of PIM2 on migration and metastasis. There is evidence to suggest that PIM2 regulates the invasion of breast cancer cells. It promotes signal transducer and activator of transcription 3 (STAT3) activity via a cytokine-dependent feedback loop, leading to STAT3 Ser727 phosphorylation and eventually to epithelial-mesenchymal transition (EMT), increased migration and invasion (26). While having observed this feedback loop previously in colorectal carcinoma cells for PIM1 (48), we did not observe any changes in STAT3 Ser272 phosphorylation in liver cancer cell lines upon PIM2 knockdown. Instead, we 
found a decreased STAT3 phosphorylation at Tyr705 (data not shown), which also modulates STAT3 transcriptional activity and has been described to be associated with migration and invasion (49). Further studies are warranted to reveal the role of PIM2 in liver cancer migration and invasion and the underlying molecular pathways.

In our mouse model of subcutaneous HepG2 xenografts, PIM2 knockdown mediated substantial anti-tumor effects, confirming that our findings from cell culture could be transferred to a complex in vivo situation. Our polymeric, PEI-based nanoparticle system for siRNA or miRNA delivery [(33,50; reviewed in ref. 51)] allowed us to specifically study in vivo effects of PIM2 knockdown, with other PIM kinases remaining unaffected. The formulation of siRNAs in a nanoparticle system addresses several shortcomings of small RNAs as drugs, including insufficient stability, delivery and cell uptake, as well as rapid elimination. In addition, the fact that the first siRNA drug has obtained market approval most recently (52) clearly indicates the potential of siRNAs for oncogene-targeting therapies.

Taken together, the findings of this study highlight the potential of targeted therapies in liver cancer that are based on the specific inhibition of PIM2. This provides the basis for further studies, aiming at a deeper exploration and understanding of the underlying molecular effects. This should be done in particular with regard to their dependency on the genetic background of the liver cancer cells, thus identifying biomarkers (e.g., p53 and $\beta$-catenin) for the efficacy of a PIM2 knockdown therapy. Furthermore, our results encourage the idea of synergistic combination therapies, utilizing PIM2 siRNAs together with other cytostatics, for example those affecting the cell cycle as well.

\section{Acknowledgements}

The authors would like to thank Dr Gerd Müller (University Clinics Leipzig, Department of Gynecology) for providing assistance with the interpretation of the cell cycle data, Markus Böhlmann and Kathrin Krause (Rudolf-Boehm-Institute for Pharmacology and Toxicology, University of Leipzig) for taking care of the animals used in this study, as well as Professor Lea Ann Dailey (Martin Luther-University Halle) for extensively proofreading the manuscript.

\section{Funding}

This study was funded by a grant from the Deutsche Krebshilfe (Az: 110992) to AA, AG and RKH.

\section{Availability of data and materials}

The datasets used during the current study are available from the corresponding author on reasonable request.

\section{Authors' contributions}

UW and AA were involved in the conception and design of the study. PK and UW were involved in the experimental procedures. All authors (PK, AG, RKH, AA and UW) were involved in the discussion of the experiments and the interpretation of the data. UW was involved in the writing of the manuscript. AA, AG, RKH and PK were involved in the revision of the manuscript. All authors have read and approved the final manuscript.

\section{Ethics approval and consent to participate}

This article does not contain any studies with human participants performed by any of the authors. All applicable international, national, and/or institutional guidelines for the care and use of animals were followed. Animal experiments were approved by the Landesdirektion Sachsen, Germany (TVV 38/16).

\section{Patient consent for publication}

Not applicable.

\section{Competing interests}

The authors declare that they have no competing interests.

\section{References}

1. Siegel RL, Miller KD and Jemal A: Cancer statistics, 2018. CA Cancer J Clin 68: 7-30, 2018.

2. Bray F, Ferlay J, Soerjomataram I, Siegel RL, Torre LA and Jemal A: Global cancer statistics 2018: GLOBOCAN estimates of incidence and mortality worldwide for 36 cancers in 185 countries. CA Cancer J Clin 68: 394-424, 2018.

3. Mondello P, Cuzzocrea S and Mian M: Pim kinases in hematological malignancies: Where are we now and where are we going? J Hematol Oncol 7: 95, 2014.

4. Warfel NA and Kraft AS: PIM kinase (and Akt) biology and signaling in tumors. Pharmacol Ther 151: 41-49, 2015.

5. Narlik-Grassow M, Blanco-Aparicio C and Carnero A: The PIM family of serine/threonine kinases in cancer. Med Res Rev 34: 136-159, 2014.

6. Zhang Y, Wang Z, Li X and Magnuson NS: Pim kinase-dependent inhibition of c-Myc degradation. Oncogene 27: 4809-4819, 2008.

7. Nair JR, Caserta J, Belko K, Howell T, Fetterly G, Baldino C and Lee KP: Novel inhibition of PIM2 kinase has significant anti-tumor efficacy in multiple myeloma. Leukemia 31: 1715-1726, 2017.

8. Grundler R, Brault L, Gasser C,Bullock AN, Dechow T, Woetzel S, Pogacic V, Villa A, Ehret S, Berridge G, et al: Dissection of PIM serine/threonine kinases in FLT3-ITD-induced leukemogenesis reveals PIM1 as regulator of CXCL12-CXCR4-mediated homing and migration. J Exp Med 206: 1957-1970, 2009.

9. Adam M, Pogacic V, Bendit M, Chappuis R, Nawijn MC, Duyster J, Fox CJ, Thompson CB, Cools J and Schwaller J: Targeting PIM kinases impairs survival of hematopoietic cells transformed by kinase inhibitor-sensitive and kinase inhibitor-resistant forms of Fms-like tyrosine kinase 3 and BCR/ABL. Cancer Res 66: 3828-3835, 2006.

10. Brault L, Gasser C, Bracher F, Huber K, Knapp S and Schwaller J: PIM serine/threonine kinases in the pathogenesis and therapy of hematologic malignancies and solid cancers. Haematologica 95: 1004-1015, 2010.

11. Keane NA, Reidy M, Natoni A, Raab MS and O'Dwyer M: Targeting the pim kinases in multiple myeloma. Blood Cancer J 5: e325, 2015.

12. van der Lugt NM, Domen J, Verhoeven E, Verhoeven E, Linders K, van der Gulden $\mathrm{H}$, Allen J and Berns A: Proviral tagging in $\mathrm{E}$ mu-myc transgenic mice lacking the Pim-1 proto-oncogene leads to compensatory activation of Pim-2. EMBO J 14: 2536-2544, 1995.

13. Allen JD, Verhoeven E, Domen J, van der Valk M and Berns A: Pim-2 transgene induces lymphoid tumors, exhibiting potent synergy with c-myc. Oncogene 15: 1133-1141, 1997.

14. Hammerman PS, Fox CJ, Cinalli RM, Xu A, Wagner JD, Lindsten $\mathrm{T}$ and Thompson CB: Lymphocyte transformation by Pim-2 is dependent on nuclear factor-kappaB activation. Cancer Res 64: 8341-8348, 2004. 
15. Lu J, Zavorotinskaya T, Dai Y, Niu XH, Castillo J, Sim J, Yu J, Wang Y, Langowski JL, Holash J, et al: Pim2 is required for maintaining multiple myeloma cell growth through modulating TSC2 phosphorylation. Blood 122: 1610-1620, 2013.

16. Asano J, Nakano A, Oda A, Amou H, Hiasa M, Takeuchi K, Miki H, Nakamura S, Harada T, Fujii S, et al: The serine/threonine kinase Pim-2 is a novel anti-apoptotic mediator in myeloma cells. Leukemia 25: 1182-1188, 2011.

17. Jimenez-Garcia MP, Lucena-Cacace A, Robles-Frias MJ, Ferrer I, Narlik-Grassow M, Blanco-Aparicio C and Carnero A: Inflammation and stem markers association to PIM1/PIM2 kinase-induced tumors in breast and uterus. Oncotarget 8: 58872-58886, 2017.

18. Wang Z, Zhang Y, Gu JJ, Davitt C, Reeves R and Magnuson NS: Pim-2 phosphorylation of p21(Cip1/WAF1) enhances its stability and inhibits cell proliferation in HCT116 cells. Int J Biochem Cell Biol 42: 1030-1038, 2010.

19. Morishita D, Katayama R, Sekimizu K, Tsuruo T and Fujita N: Pim kinases promote cell cycle progression by phosphorylating and down-regulating $\mathrm{p} 27 \mathrm{Kip} 1$ at the transcriptional and posttranscriptional levels. Cancer Res 68: 5076-5085, 2008.

20. Yan B, Zemskova M, Holder S, Chin V, Kraft A, Koskinen PJ and Lilly M: The PIM-2 kinase phosphorylates BAD on serine 112 and reverses BAD-induced cell death. J Biol Chem 278: 45358-45367, 2003.

21. Fox CJ, Hammerman PS, Cinalli RM, Master SR, Chodosh LA and Thompson CB: The serine/threonine kinase Pim-2 is a transcriptionally regulated apoptotic inhibitor. Genes Dev 17: $1841-1854,2003$

22. Hospital MA, Jacquel A, Mazed F, Saland E, Larrue C, Mondesir J, Birsen R, Green AS, Lambert M, Sujobert P, et al: RSK2 is a new Pim2 target with pro-survival functions in FLT3-ITD-positive acute myeloid leukemia. Leukemia 32: 597-605, 2018

23. Ramachandran J, Santo L, Siu KT, Panaroni C and Raje N: Pim2 is important for regulating DNA damage response in multiple myeloma cells. Blood Cancer J 6: e462, 2016.

24. Yang T, Ren C, Qiao P, Han X, Wang L, Lv S, Sun Y, Liu Z, Du Y and Yu Z: PIM2-mediated phosphorylation of hexokinase 2 is critical for tumor growth and paclitaxel resistance in breast cancer. Oncogene 37: 5997-6009, 2018.

25. Musiani D, Hammond DE, Cirillo L, Erriquez J, Olivero M, Clague MJ and Di Renzo MF: PIM2 kinase is induced by cisplatin in ovarian cancer cells and limits drug efficacy. J Proteome Res 13: 4970-4982, 2014

26. Uddin N, Kim RK, Yoo KC, Kim YH, Cui YH, Kim IG, Suh Y and Lee SJ: Persistent activation of STAT3 by PIM2-driven positive feedback loop for epithelial-mesenchymal transition in breast cancer. Cancer Sci 106: 718-725, 2015.

27. Narlik-Grassow M, Blanco-Aparicio C, Cecilia Y, Peregrina S, Garcia-Serelde B, Muñoz-Galvan S, Cañamero M and Carnero A: The essential role of PIM kinases in sarcoma growth and bone invasion. Carcinogenesis 33: 1479-1486, 2012.

28. Chen J and Yang X: The role of Pim-2 in apoptotic signal transduction pathway of hepatocellular carcinoma. Int Surg J 4: 1380 2017.

29. Ren K, Zhang W, Shi Y and Gong J: Pim-2 activates API-5 to inhibit the apoptosis of hepatocellular carcinoma cells through NF-kappaB pathway. Pathol Oncol Res 16: 229-237, 2010.

30. Gong J, Wang J, Ren K, Liu C, Li B and Shi Y: Serine/threonine kinase Pim-2 promotes liver tumorigenesis induction through mediating survival and preventing apoptosis of liver cell. J Surg Res 153: 17-22, 2009.

31. Ren K, Duan W, Shi Y, Li B, Liu Z and Gong J: Ectopic over-expression of oncogene Pim-2 induce malignant transformation of nontumorous human liver cell line L02. J Korean Med Sci 25: 1017-1023, 2010

32. Livak KJ and Schmittgen TD: Analysis of relative gene expression data using real-time quantitative PCR and the 2(-Delta Delta C(T)) method. Methods 25: 402-408, 2001

33. Hobel S, Koburger I, John M, Czubayko F, Hadwiger P, Vornlocher HP and Aigner A: Polyethylenimine/small interfering RNA-mediated knockdown of vascular endothelia growth factor in vivo exerts anti-tumor effects synergistically with Bevacizumab. J Gene Med 12: 287-300, 2010.
34. Liu Z, Liu H, Yuan X, Wang Y, Li L, Wang G, Song J, Shao Z and Fu R: Downregulation of Pim-2 induces cell cycle arrest in the G0/G1 phase via the p53-non-dependent p21 signaling pathway. Oncol Lett 15: 4079-4086, 2018.

35. Yew TL, Chiu FY, Tsai CC, Chen HL, Lee WP, Chen YJ, Chang MC and Hung SC: Knockdown of p21(Cip1/Waf1) enhances proliferation, the expression of stemness markers, and osteogenic potential in human mesenchymal stem cells. Aging Cell 10: 349-361, 2011

36. Nawijn MC, Alendar A and Berns A: For better or for worse: The role of Pim oncogenes in tumorigenesis. Nat Rev Cancer 11: 23-34, 2011.

37. Levy D, Davidovich A, Zirkin S, Frug Y, Cohen AM, Shalom S and Don J: Activation of cell cycle arrest and apoptosis by the proto-oncogene Pim-2. PLoS One 7: e34736, 2012.

38. Adam K, Cartel M, Lambert M, David L, Yuan L, Besson A, Mayeux P, Manenti S and Didier C: A PIM-CHK1 signaling pathway regulates PLK1 phosphorylation and function during mitosis. J Cell Sci 131: pii: jes213116, 2018.

39. Kreuz S, Holmes KB, Tooze RM and Lefevre PF: Loss of PIM2 enhances the anti-proliferative effect of the pan-PIM kinase inhibitor AZD1208 in non-Hodgkin lymphomas. Mol Cancer 14: 205, 2015 .

40. Pellegrino R, Calvisi DF, Ladu S, Ehemann V, Staniscia T, Evert M, Dombrowski F, Schirmacher P and Longerich T: Oncogenic and tumor suppressive roles of polo-like kinases in human hepatocellular carcinoma. Hepatology 51: 857-868, 2010.

41. Liu Z, Sun Q and Wang X: PLK1, A potential target for cancer therapy. Transl Oncol 10: 22-32, 2017.

42. Waisberg $\mathbf{J}$ and Saba GT: Wnt-/- $\beta$-catenin pathway signaling in human hepatocellular carcinoma. World J Hepatol 7: 2631-2635, 2015.

43. Vilchez V, Turcios L, Marti F and Gedaly R: Targeting Wnt/ $\beta$-catenin pathway in hepatocellular carcinoma treatment World J Gastroenterol 22: 823-832, 2016.

44. de La Coste A, Romagnolo B, Billuart P, Renard CA, Buendia MA, Soubrane O, Fabre M, Chelly J, Beldjord C, Kahn A and Perret C: Somatic mutations of the beta-catenin gene are frequent in mouse and human hepatocellular carcinomas. Proc Natl Acad Sci USA 95: 8847-8851, 1998.

45. Ding Z, Shi C, Jiang L, Tolstykh T, Cao H, Bangari DS, Ryan S, Levit M, Jin T, Mamaat K, et al: Oncogenic dependency on $\beta$-catenin in liver cancer cell lines correlates with pathway activation. Oncotarget 8: 114526-114539, 2017.

46. Schmucker S and Sumara I: Molecular dynamics of PLK1 during mitosis. Mol Cell Oncol 1: e954507, 2014.

47. Katyal S, Oliver JH III, Peterson MS, Ferris JV, Carr BS and Baron RL: Extrahepatic metastases of hepatocellular carcinoma. Radiology 216: 698-703, 2000

48. Weirauch U, Beckmann N, Thomas M, Grünweller A, Huber K, Bracher F, Hartmann RK and Aigner A: Functional role and therapeutic potential of the pim-1 kinase in colon carcinoma. Neoplasia 15: 783-794, 2013.

49. Kamran MZ, Patil P and Gude RP: Role of STAT3 in cancer metastasis and translational advances. Biomed Res Int 2013: 421821,2013

50. Ibrahim AF, Weirauch U, Thomas M, Grunweller A, Hartmann RK and Aigner A: MicroRNA replacement therapy for miR-145 and miR-33a is efficacious in a model of colon carcinoma. Cancer Res 71: 5214-5224, 2011.

51. Hobel S and Aigner A: Polyethylenimines for siRNA and miRNA delivery in vivo. Wiley Interdiscip Rev Nanomed Nanobiotechnol 5: 484-501, 2013.

52. Wood H: FDA approves patisiran to treat hereditary transthyretin amyloidosis. Nat Rev Neurol 14: 570, 2018.

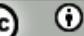

This work is licensed under a Creative Common Attribution 4.0 International (CC BY 4.0) License. 